\title{
Studi Avifauna Gunung Lawu Berdasarkan Distribusi Altitudinal
}

\author{
DEWI PUSPITA SARI ${ }^{1}$, PUGUH KARYANTO $^{1}$, MUZAYYINAH $^{1}$ \\ ${ }^{1}$ Program Studi Pendidikan Biologi FKIP, Universitas Sebelas Maret Surakarta \\ J1. Ir. Sutami 36 A Kentingan Surakarta, Jawa Tengah 57126 \\ email: dewibioedu@gmail.com
}

\begin{abstract}
Mount lawu is the ekoton area that administratively located between Central Java and East Java Province. Research was done in qualitative exploration by using a series of the observation and identification methods. Sampling techniques used in line transect famous with the crusier method. There are four routes of climb as the location sampling: 1) Cemoro kandang (Karanganyar, Central Java), (2) Tambak (Karanganyar, Central Java), (3) Cemoro Sewu (Magetan, East Java) and (4). Jogorogo (Ngawi, East Java). Validation data was undertaken with triangulation method. Technique data were analyzed by using in descriptive qualitative. Based on the research done inferred the type of highest species found at 1900-2100 masl, while the lowest species types found at an altitude of 3100-3275 masl. Turdus poliocephalus stresmanii having spesification location foraging upon 2500-3268 masl, Apus affinis with 900-1700 masl, Cettia volcania in 3265 masl, and finnaly Falco peregrinus and Treron sphenura 3100 masl are bird with spesific distribution. Other kinds is cosmopolite by the span of distribution a relatively large amount of.
\end{abstract}

Keywords: altitude distribution, avifauna, line transect, Mount Lawu

\section{PENDAHULUAN}

Kekayaan avifauna indonesia tercermin dari kepemilikan 1.539 jenis burung yang merupakan $17 \%$ dari total burung di dunia. Data menunjukkan 104 jenis burung di Indonesia dalam kondisi terancam punah. $17 \%$ diantaranya adalah jenis endemik, sekitar 15,4\% mengalami status genting, dan sisanya masuk dalam kategori rentan (Sujatnika dalam Setiadi, 2003). Jenis avifauna yang dijumpai pada kawasan Jawa dan Bali sebanyak 494 jenis. Jumlah tersebut mencakup setengah dari famili burung di dunia. Jenis avifauna yang dijumpai dibedakan menjadi 2 kelompok, yaitu burung penetap (368 spesies, 24 endemik) dan burung migran (126 spesies).

Distribusi burung berdasarkan ketinggian telah banyak dipelajari di Pulau Jawa. Hasil analisis menunjukkan 420 spesies burung ditemukan pada ketinggian antara $0-800 \mathrm{~m}$ dpl. 300 spesies burung menjadi penghuni di ketinggian 800-2000 m dpl. Dengan memperhatikan ketinggian maksimal dimana masih ditemukan jenis burung yang hidup tampak bahwa ada suatu daerah utama pada ketinggian 1.300-1.600 m dpl dijumpai 150 spesies yang mencapai ketinggian maksimalnya. Keanekaragaman jenis burung pada tipe hutan pegunungan basah masih cukup tinggi dan terdapat jenis endemik yang menarik dalam jumlah relatif banyak (MacKinnon, 1995).

Propinsi Jawa Tengah secara ekologi memiliki perbedaan dengan Jawa Timur serta dengan Jawa Barat dan Banten. Propinsi ini merupakan daerah peralihan antara iklim di Jawa Timur yang cenderung kering dan gersang dengan iklim di Jawa Barat dan Banten yang cenderung basah dan lembab,sehingga di propinsi ini ditemui spesies- spesies tumbuhan, hewan atau mikrobia yang melimpah di Jawa Timur namun tidak ditemukan secara alami di Jawa Barat, misalnya pohon cemara gunung (Casuarina junghuhniana) atau sebaliknya melimpah di Jawa Barat dan Banten tetapi tidak dijumpai secara alami di Jawa Timur, misalnya pohon rasamala (Altingia exselsa) (Steenis, 1972).

Salah satu kawasan di pulau Jawa dengan potensi avifauna adalah Gunung Lawu. Avifauna Gunung Lawu belum banyak diteliti, bebrapa kajian yang telah dilakukan 
lebih terfokus pada jenis endemik tertentu, misalnya Jalak Lawu (Turdus poliochepalus stresmanii) dan Ayam hutan merah (Gallus gallus) (Soenarto dalam Prasetyanto, 2005; Budiharjo, 2005).

Kompleks Gunung Lawu mempunyai hutan dengan luas 24. 187,5 ha. Luasan hutan tersebut dapat diklasifikasikan ke dalam beberapa kategori yaitu daerah terbuka, daerah dengan vegetasi jarang, vegetasi agak jarang, vegetasi agak lebat, dan lebat (Rahayu dkk., 2006). Selain tingkat kelebatan vegetasi, beberapa fenomena terkait dengan dominasi vegetasi pada ketinggian tertentu, misalnya di bagian kaki gunung tersusun atas perkebunan sayur dan hutan budidaya pinus, kemudian pada ketinggian diatasnya dijumpai hutan serasah terdegradasi dengan tanaman dominan berupa tanganan (Schlefera sp.) dan kayu pasang (Lithocarpus pruinosa), serta pada areal puncak didominasi ilalang sabana (Festuca nibigena) dan edelweiss (Anaphalis javanica). Perbedaan dalam kedua hal tersebut memberikan variasi pada komposisi dan keanekaragaman burung (Soendjoto, 2003).

Secara keseluruhan hutan di Gunung Lawu meliputi areal seluas lebih dari 15.000 ha. Luas ini dapat bertambah apabila diikutsertakan hutan pada ketinggian yang lebih rendah. Bentangan topografi Gunung Lawu sangat khas sehingga mampu mengkondensasi angin tenggara yang basah menjadi hujan. Hal ini menyebabkan lereng selatan relatif subur dengan vegetasi yang rapat, sekalipun musim kemarau (Setiawan, 2001).

\section{METODE}

Penelitian bersifat deskriptif kualitatif dengan menggunakan strategi yang mengacu pada penelitian eksploratif. Kegiatan di lapangan dibagi menjadi empat kegiatan, antara lain:
Penentuan lokasi pengambilan sampel. Jalur yang diambil untuk distribusi altitudinal dicuplik dari area yang mengelilingi Gunung Lawu. Empat jalur pendakian dari berbagai sisi dengan entitas berdasar pada perbedaan ketinggian (dibuat dengan jarak pengamatan dalam tallysheet sepanjang $200 \mathrm{~m}$ dpl) dan agihan flora.

Pengambilan sampel. Metode yang digunakan adalah line transect dengan belt transect terintegrasi. Burung yang diamati berada pada rute dan di kanan kiri dari jalur dengan radius pandangan mata. Kesukaran pengenalan burung secara individu diatasi dengan asumsi bahwa setiap individu yang dijumpai di suatu habitat pada waktu dan ketinggian berbeda merupakan individuindividu yang berbeda. Asumsi pendukung dibuat untuk menghindari data yang bias: a) burung yang dijumpai di dalam rute semuanya terdeteksi, b) interval jarak yang digunakan harus akurat, d) burung terdeteksi secara individual, e) data yang bias dari observer, musim, dan cuaca dimaklumi atau dengan kata lain kegagalan dari asumsi tersebut tidak berkaitan dengan habitat maupun unsur penelitian.

Identifikasi sampel. Identifikasi meliputi morfologi, warna, maupun perilaku. Selain itu dapat dilakukan melalui suara apabila observer tidak dapat melihat objek secara langsung. Kegiatan dilakukan dengan mencocokkan fakta lapang, sketsa, dokumentasi foto dengan sumber pustaka yang ada seperti buku panduan lapang dari John MacKinnon maupun dari Derek Holmes adn Stephen Nash. Identifikasi dilakukan sampai tingkat terendah dari hierarki taksonomi, kemudian dibuat list.

Pengukuran faktor lingkungan. Alat yang digunakan adalah termometer, higrometer, luxmeter, GPS Elektrik. Penutupan vegetasi dilakukan dengan pembuatan interval kerapatan vegetasi. 
HASIL

Tabel 1. Ketinggian dengan jumlah spesies burung

Ketinggian (m dpl) Jenis Burung

Apus affinis, Copsycus saularis, Lanius schach, Parus major, Prinia familiaris,

900-1100 Pycnonotus aurigaster, Pyloscopus trivirgatus, Streptopelia bitorquita, Zosterops palpebrosus

Aethopyga eximia, Apus affinis, Collocalia esculenta, Cuculus soneratii, Lacedo

1100-1300 pulchella, Lanius schach, Lophozosterops javanicus, Loriculus pusillus,

Pericrocotus flameus, Pycnonotus aurigaster, Pyloscopus trivirgatus,

Streptopelia bitorquita, Zosterops palpebrosus

Apus affinis, Copsycus saularis, Dendrocopus macei, Ficedula mugimaki,

1300-1500 Halcyon chloris, Ichtinaetus malayensis, Lacedo pulchella, Lanius schach, Parus major, Pericrocotus flameus, Pericrocotus miniatus, Pycnonotus aurigaster, Pyloscopus trivirgatus, Rhipidura euryura, Sturnus contra, Zosterops palpebrosus

Aethopyga eximia, Dendrocopus macei, Lalage nigra, Lophozosterops javanicus,

1500-1700 Pericrocotus miniatus, Picoides molucensis, Prinia familiaris, Pterutus flaviscapis, Pyloscopus trivirgatus

Aegithina tipia, Aethopyga eximia, Apus affinis, Copsycus saularis, Cuculus sepulcralisFicedula mugimaki, Ichtinaetus malayensis, Lanius schach,

1700-1900 Lophozosterops javanicus, Macropygia unchall, Parus major, Pericrocotus flameus, Pericrocotus miniatus, Prinia familiaris, Pycnonotus aurigaster, Pyloscopus trivirgatus, Rhipidura phoenicura, Sturnus contra, Treron griseicauda, Zosterops montanus, Zosterops palpebrosus

Aegithina tipia, Aethopyga eximia, Caprimulgus pulchelus, Copsycus saularis, Cucuclus saturatus, Dendrocopus macei, Ficedula mugimaki, Lalage nigra, Lanius schach, Lophozosterops javanicus, Macropygia emilliana, Macropygia

1900-2100 ruficeps, Macropygia unchall, Muscicapa daunrica, Orthotomus cuculatusParus major, Pericrocotus miniatus, Prinia familiaris, Pterutus flaviscapis, Pycnonotus aurigaster, Pyloscopus trivirgatus, Rhipidura phoenicura,Sitta azurea, Sitta frontalis, Treron grisecauda, Zosterops palpebrosus

Collocalia esculenta, Copsycus saularis, Dicaecum sanguinolentum, Falco peregrinus, Ichtinaetus malayensis, Lacedo pulchella, Lanius schach,

2100-2300 Macropygia emilliana, Macropygia unchall, Oriolus chinensis, Pycnonotus aurigaster, Rhinomyias olivacea, Rhipidura javanica, Rhipidura phoenicura, Sturnus contra, Zosterops palpebrosus

Aethopyga eximia, Copsycus saularis, Lophozosterops javanicus, Macropygia

2300-2500 emilliana, Macropygia ruficeps, Oriolus chinensis, Parus major, Pericrocotus flameus, Sturnus contra,Zosterops montanus, Zosterops palpebrosus Aethopyga eximia, Copsycus saularis, Macropygia unchall, Pericrocotus

2500-2700 flameus, Pericrocotus miniatus, Treron griseicauda, Turdus poliochepalus stresmanii, Zosterops montanus, Zosterops palpebrosus Aethopyga eximia, Cuculus saturataus, Dicaecum sanguinolentum, Oriolus

2700-2900 chinensis, Treron sphenura, Turdus poliochepalus stresmanii, Zosterops montanus

2900-3100 Cettia volcania, Falco peregrinus,Muscicapa dauurica,Treron griseicauda, Treron sphenura, Turdus poliochepalus stresmanii, Zosterops montanus

3100-3275 Cettia volcania, Lophozosterops javanicus, Turdus poliochepalus stresmanii, Zosterops montanus 


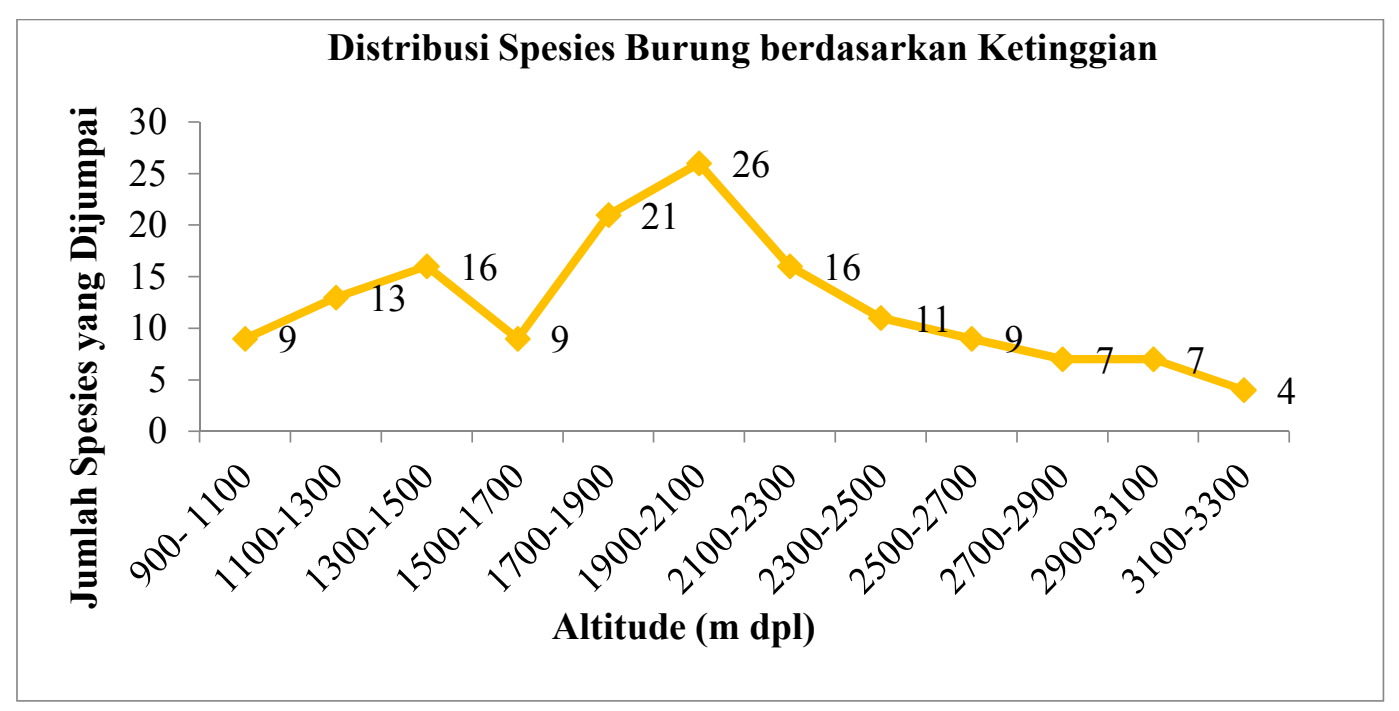

Gambar 1. Grafik jumlah spesies Burung berdasarkan ketinggian (per $200 \mathrm{~m}$ dpl) pada empat jalur pendakian

\section{PEMBAHASAN}

Gunung Lawu merupakan salah satu gunung dipulau Jawa yang umumnya memiliki zonasi pegunungan dengan spesies burung yang spesifik di setiap ketinggian. Gunung Lawu mempunyai kawasan hutan Dipteropkarp Bukit, hutan Dipterokarp Atas, Hutan Montana. Hutan Gunung lawu memiliki karakteristik hutan tropika basah (Bussmann, 2001). Komposisi nya antara lain a) Hutan Dipteropkarp Bukit adalah kawasan hutan yang terdapat pada ketinggian 300-750 m dpl. Menurut whitten et al, (1996) b) hutan Dipterocarp atas kawasan hutan yang terdapat pada ketinggian 750-1200 m dpl dengan dominasi Scima walichii, c) hutan Montana merujuk pada kawasan hutan yang terdapat pada ketinggian 1200-2400 $\mathrm{m}$ dpl dan d) lebih dari $2400 \mathrm{~m}$ dpl sebagai zona sub alpin.

Distribusi terbatas pada kondisi ketinggian tertentu dapat terekam dari data yang disajikan. Kawasan dengan ketinggian 900-1700 m dpl keanekaragaman burung relatif fluktuatif karena adanya alih fungsi hutan menjadi ladang pertanian sayur dan perkebunan budidaya Pinnus merkusii. Alih fungsi lahan mengakibatkan ketidakstabilan habitat, sehingga suplai makanan kurang beragam. Mulai ketinggian 1700-2100 m dpl termasuk daerah hutan montana. Sampel vegetasi di berbagai jalur pendakian menunjukkan areal hutan yang relatif heterogen dengan kompleksitas struktur vegetasi dan kerapatan yang relatif tinggi, selain itu pada jalur Jogorogo dan Cemoro Sewu juga dijumpai sumber mata air. Penutupan vegetasi memberikan kontribusi pada konservasi telur maupun anakan dari gangguan predator alaminya sehingga tingkat kesuksesan reproduksinya lebih tinggi. Sebaliknya jika kompleksitas struktur vegetasi di daerah tersebut menurun maka variasi niche bagi burung juga sedikit dan akan meangakibatkan penurunan keanekaragaman burung.

Kondisi ini berbeda dengan hasil penelitian Hoogerwef yang diacu oleh Whitten et al (1996). Studi yang sudah dilakukan di Pulau Jawa menunjukkan bahwa daerah utama bagi burung yang keanekaragamannya cukup tinggi ditemukan pada ketinggian antara 1300-1600 m dpl. Kondisi ini menunjukkan bahwa burungburung di Jawa hidup di hutan-hutan pegunungan dan beberapa diantaranya hidup terbatas di tempat tersebut. Perbedaan ini dapat dimaklumi karena kondisi fisik yang heterogen pada setiap gunung.

Keanekaragaman terendah dijumpai pada ketinggian 3100-3275 m dpl. Kawasan yang teridentifikasi sebagai zona sub alpin didominasi oleh tanaman cantigi (Vaccinium sp.), senduro (Anaphalis longifolia), edelweis (Anaphalis javanica) dengan kombinasi berbagai lichen dan lumut. Kondisi ini muncul karena disebabkan beberapa faktor 
antara lain semakin tinggi suatu tempat maka terjadi penurunan variasi habitat, penutupan awan sehingga mereduksi penetrasi cahaya, kemiringan dan kecuraman lereng, yang pada akhirnya menyebabkan kenaikan spesialisasi makanan. Beberapa jenis burung menunjukkan tingkat endemisitas yang tinggi seperti pada Turdus poliochepalus stresmanii.

Kualitas dan kuantitas makanan merupakan faktor pembatas yang sangat penting pada kesuksesan regenerasi. Pengaruh sumber makanan menimbulkan asosiasi antara struktur vegetasi dengan keanekaragaman jenis burung. Tingkat nutrisi yang rendah pada suatu vegetasi merupakan faktor penyebab rendahnya kerapatan dan keanekaragaman jenis burung. Turdus poliochepalus stresmanii dijumpai pada ketinggian 2500-3265 mdpl. Fenomena ini terjadi karena adanya korelasi positif antara spesies tersebut dengan vegetasi sub alpin yang didominasi cantigi dan manisrejo sebagai sumber makanan. Berdasarkan pengamatan, pohon cantigi merupakan pohon inang yang digunakan untuk membuat sarang. Pohon yang dipilih untuk bersarang selalu memiliki beberapa persamaan tipe, yaitu memiliki percabangan banyak. Menurut Budiharjo (2005) sekitar 60\% shelter berada di pohon atau perdu yang buahnya merupakan salah satu jenis makanannya. Turdus memiliki perilaku tidak suka terbang jauh dan lebih bnayak berda di permukaan tanah untuk mengambil biji, invertebrata tanah bahkan mie instan sisa para pendaki gunung. Selain jenis tersebut, Apus affinis juga hanya dijumpai pada area lower-middle mountain forest (900-2700 m dpl). Kondisi ini terjadi karena adanya pengaruh penutupan dan keragaman vegetasi bawah yang masih tinggi sehingga menyediakan shelter yang nyaman (MacKinnon, 1995). Pada ketinggian $3100 \mathrm{~m}$ dpl dijumpai spesies Falco peregrinus dan Treron sphenura dimana spesies ini juga terdistribusi karena pemenuhan makanan dan juga ketersediaan nesting. Kedua spesies ini juga menunjukkan fenomena predasi dimana Falco merupakan predator dari famili columbidae terutama jenis Treron (MacKinnon, 1995).
Famili Zoostepsidae memiliki rentang disribusi yang luas. Kondisi ini disebabkan karena koloni yang terbentuk memaksimalkan eksploitasi aneka macam makanan. Menurut Krebs (2001), kesuksesan pemencaran individu ataupun koloni diikuti oleh suksesnya perkembangbiakan dan kesuksesan melewati barier berpa kemiringan dan kondisi geografis.

\section{KESIMPULAN}

Jumlah jenis burung tertinggi dijumpai pada ketinggian 1900-2100 m dpl, sedangkan jumlah jenis spesies terendah dijumpai pada ketinggian 3100-3275 m dpl. Jenis Turdus poliocephalus stresmanii memiliki spesifikasi lokasi jelajah pada 2500-3265 mdpl, Apus affinis 900-1700 m dpl, Cettia volcania 3265 $\mathrm{m}$ dpl, Falco peregrinus dan Treron sphenura $3100 \mathrm{~m}$ dpl merupakan burung dengan distribusi altitudinal yang spesifik. Jenis lain seperti Zoosterops palpebrosus bersifat kosmopolit dengan rentang distribusi yang relatif luas.

\section{DAFTAR PUSTAKA}

Budiharjo A. 2005. Pola Reproduksi Burung Jalak Gading (Turdus sp.) di Gunung Lawu, Jawa Tengah. Biodiversitas. vol 6 (4): 272- 275.

Bussmann RW. 2001. Vegetation Ecology and Regeneration of Tropical Mountain Forest. Bayreuth: Departement of Plant Physiology, University of Bayreuth.

Krebs CJ. 2001. Ecology The Experimental Analysis od Distribution and Abundance $2^{\text {nd }}$ Edition. New York: Harper and Row Publ.

MacKinon J, Phillips K, Van Balen B. 2000. Burung-burung di Sumatra, Jawa, Bali, dan Kalimantan (termasuk Sabah, Serawak, dan Brunei Darussalam). Jakarta: Puslitbang-LIPI.

MacKinnon J. 1995. Burung- Burung di Jawa dan Bali. Jakarta: Puslitbang-LIPI.

Rahayu, Puguh K, Seyo, Rara. 2006. Laporan Penelitian Profil Keanekaragaman Flora Fauna, Peta Penutupan Vegetasi, Kerusakan Lingkungan, dan Konsep 
Pengembangan Ekowisata di Gunung Lawu. Surakarta: LPPM UNS.

Setiadi A. 2003. Status, Distribusi, Populasi, dan Konservasi Elang Jawa di Jawa Barat Bagian Selatan. Bandung: Yayasan Pribumi Alam Lestari.
Soendjoto MA. 2003. Keanekaragaman Burung di Enam Tipe Habitat PT Inhutani Labanan, Kalimantan Timur. Biodiversitas. vol 4 (2): 104- 105.

Whitten T, Soeriatmadja RE, Afiff SA. 1996. The Ecology of Java and Bali. Vol II Periplus Edition (Hk) ltd. Singapore. 